\title{
ANALYZING THE PARAMETERS AFFECTING THE QUALITY OF REFUSE DERIVED FUEL PELLETS DERIVED FROM MUNICIPAL SOLID WASTE
}

\author{
MARYAM MUAYAD ${ }^{1, *}$, QABAS ABbas ${ }^{* *}$ and ZAHRAA ABDULKADER ${ }^{* * *}$ \\ *College of Civil Engineering, AUIS-Iraq \\ ${ }^{* *}$ College of Energy Engineering, AUIS-Iraq \\ ${ }^{* *}$ College of Energy Engineering, AUIS-Iraq
}

(Accepted for Publication: December 8, 2020)

\begin{abstract}
One of the major factors that play a role in threatening our climate maintenance is the non-ecofriendly energy production and finding an alternative to this is essential. Refuse-derived fuel (RDF) is an alternative process for non-ecofriendly energy production in which fuel is produced from various types of local waste, including municipal solid waste (MSW). It diverts the landfill waste into a source of energy supplier. This review paper examines the parameters that affect the quality of the Refuse-derived fuel (RDF) that is derived from municipal solid waste (MSW) by reviewing prior studies from multiple sources; experiment-based research papers. The examined parameters from the collected data which included the moisture content, the ash content, Calorific value, Sulfur content, Chlorine content, Carbon content, as well as the content of heavy metals; Cadmium (Cd), Chromium (Cr), Nickel $(\mathrm{Ni})$, Silver (Ag), Zinc ( $\mathrm{Zn})$, Lead (Pb), Copper (Cu), and Arsenic (As) were descriptively analyzed in comparison to the typical contents found in the Refuse-derived fuel (RDF) as these typical contents determine the quality of these pellets for producing energy. Some of the collected data for some parameters fell within their typical range. Yet, some did not.
\end{abstract}

KEYWORDS: Climate Change; Energy Production Alternatives; Waste Recycling; Environment Sustainability; Environmental Engineering.

\section{INTRODUCTION}

Climate change has globally been a international society. It causes the melting of polar ice caps and this on its part increases sea levels. Also, climate change is related to warming the earth and as a result, some regions will fall into the reduction of crops harvest as some crops will not cope with the increase in temperature. Moreover, climate change could cause the rise of some diseases and water-prone illnesses (Abraham et al., 2014; Riedy, 2016).

The accumulation of waste is related directly to this issue. Wastes are usually either disposed of in sites to be burned or buried as a way to get rid of them or recycled and this method, recycling, is not useful as not all the waste materials can be recycled. Burning waste had an impact on natural greenhouse gases (GHG) and caused the emission of more carbon dioxide and methane gases. High amounts of greenhouse gases played a role in rising the temperature on earth and melting the ice (Adedeji et al., 2014; Riedy, 2016). Also, heavy metals such as Lead, Mercury, Cadmium, Chromium, and some other heavy elements are found in industrial and commercial waste mostly. They are toxic to the soil, human beings, animals, and plants, "These metallic elements are considered systemic toxicants that are known to induce multiple organ damage, even at lower levels of exposure" (Singh et al., 2011; Tchounwou et al., 2012; Asati et al., 2016). 
Waste to Energy (WTE) technologies could be replacement methods for deriving energy in a healthier way to the environment. For waste to be converted into a different form of energy, some conversion methods could be implemented to get these forms of energy. These conversion methods could include "Thermochemical conversion", "Physicochemical Conversion", and "Biochemical Conversion". These conversion methods had different energy deriving processes as they could produce different forms of energy and products including heat, electricity, liquid biofuels, solid fuels, industrial materials, and solid conditioners. RDF pellets fall within the Thermochemical conversion method that results in the production of heat and electricity (Seltenrich, 2016; Malinauskaite et al., 2017).

The Refuse-derived fuel (RDF) is an alternative process for non-ecofriendly energy production in which fuel is produced from various types of local waste, including municipal solid waste (MSW), industrial waste, non-recycling materials, and commercial waste through several recycling methods; a mix of mechanical and biological treatment methods that include shredding, digesting, magnetic separation, Eddy current separation, Trommel screening and finally the production of the pellets (Hernandez-Atonal et al., 2006) which will be used in different forms of applications to produce different forms of energy and products as it will be a source for electricity and heat; it will act as an alternative to coal-based energy production and cement kilns (Sapuay, 2015; Hemidat et al., 2019). The RDF pellets are good alternatives for various fuels as it uses most of the waste that is being disposed of; avoiding the negative impacts of landfilling and other forms of polluting the environment.

This paper will examine the parameters that could identify the quality of RDF pellets when produced from municipal solid waste (MSW) by reviewing multiple sources based on that issue as it will describe the typical ranges and the properties of each parameter affecting the quality of RDF pellets.

\section{MANUFACTURING PROCESS OF THE REFUSE-DERIVED FUEL (RDF) FROM MUNICIPAL SOLID WASTE (MSW)}

Refuse-derived fuel is typically derived from municipal solid waste (MSW) by undergoing different processes respectively including Shredding, Digestion Tower, Magnetic separation, Eddy current separation, Trommel Screening, and lastly the pelletizer (Hernandez-Atonal et al., 2006; Fitzgerald et al., 2009).

In Sulaimani city, the Refuse-derived fuel is derived from the municipal solid waste (MSW) by undergoing the following processes respectively (Sarwar, 2020).

-Shredding in which the municipal solid waste (MSW) size becomes less than $30 \mathrm{~cm}$.

- Trommel screening in which the MSW is separated according to their size in which the MSW that is less than $30 \mathrm{~cm}$ moves to the next step in contrast to those which are greater than $30 \mathrm{~cm}$.

-Bio-drying in which the MSW is fully dried up from any liquid it used to contain.

\section{CHARACTERIZATION OF THE REFUSE-DERIVED FUEL (RDF) FROM MUNICIPAL SOLID WASTE (MSW)}

This paper is a reviewed-research based paper; the collected data were constructed from previous experiments on RDF pellets in different countries that aimed to replace the energy produced from conventional fuels by the energy produced through the production process of RDF pellets. It also focuses on the environmental impact of RDF pellets as this process reduces the municipal solid waste being piled up in landfills. 


\subsection{Data Collection}

The data that were selected were collected from the European Commission that included data from all across Europe, Marmara Research Center in Turkey, Sheffield University in the UK, the University of Jordan in Jordan, and the University of Rome in Italy.

\subsection{Data Analysis}

Chemical properties of RDF pellets were selected from these research papers as these properties determine the use, the application, and the quality of RDF pellets. These properties included the moisture content, the ash content,
Calorific value, Sulfur content, Chlorine content, Carbon content, as well as the content of heavy metals; Cadmium (Cd), Chromium (Cr), Nickel $(\mathrm{Ni})$, Silver $(\mathrm{Ag})$, Zinc $(\mathrm{Zn})$, Lead $(\mathrm{Pb})$, Copper $(\mathrm{Cu})$, and Arsenic (As). The selected properties were illustrated in the form of charts that convey the average value of these properties from all the selected research papers.

This paper deduces the quality of the Refuse-derived Fuel by identifying the typical ranges of each of the selected parameters that are derived from MSW.

\section{LITERATURE REVIEW}

Table (1): RDF Pellets Analysis

\begin{tabular}{|c|c|c|c|c|c|c|c|c|c|c|c|c|c|c|c|}
\hline \multirow[t]{4}{*}{ References } & \multicolumn{2}{|c|}{ Immediate Analysis } & $\begin{array}{l}\text { Calorific } \\
\text { Property }\end{array}$ & \multicolumn{3}{|c|}{$\begin{array}{c}\text { Elementary } \\
\text { Analysis }\end{array}$} & \multicolumn{8}{|c|}{ Trace Element Analysis } & $\begin{array}{c}\text { Types of } \\
\text { Waste } \\
\text { (output) }\end{array}$ \\
\hline & Moisture\% & Ash\% & $\begin{array}{l}\text { Calorific } \\
\text { Value }\end{array}$ & $\mathrm{S} \%$ & $\begin{array}{l}\mathrm{Cl} \\
\%\end{array}$ & $\mathrm{C} \%$ & $\begin{array}{l}\mathrm{Cd} \\
(\mathrm{m}\end{array}$ & $\begin{array}{l}\mathrm{Cr} \\
(\mathrm{m}\end{array}$ & $\begin{array}{l}\mathrm{Ni} \\
(\mathrm{m}\end{array}$ & $\begin{array}{l}\mathrm{Hg} \\
(\mathrm{mg} /\end{array}$ & $\begin{array}{l}\mathrm{Zn} \\
(\mathrm{mg} /\end{array}$ & $\begin{array}{c}\mathrm{Pb} \\
(\mathrm{mg} / \mathrm{k}\end{array}$ & $\begin{array}{c}\mathrm{Cu} \\
(\mathrm{mg} / \mathrm{k}\end{array}$ & $\begin{array}{c}\text { As } \\
(\mathrm{mg} / \mathrm{kg})\end{array}$ & \\
\hline & & & $\mathrm{MJ} / \mathrm{kg}$ & & & & $g / k$ & $g / k$ & $g / k$ & $\mathrm{~kg})$ & $\mathrm{kg})$ & g) & g) & & \\
\hline & & & & & & & g) & g) & g) & & & & & & \\
\hline \multirow{8}{*}{$\begin{array}{l}\text { Gendebien et al, } \\
2003\end{array}$} & 13.4 & 13.8 & 20.6 & 0.1 & 0.7 & $* * *$ & 2.2 & 48 & 13. & 0.2 & $* \star *$ & 89 & 97.5 & 1 & Demolition \& \\
\hline & & & & & & & & & 1 & & & & & & Commercial \\
\hline & & & & & & & & & & & & & & & Waste \\
\hline & 24.7 & 16 & 13.3 & 0.2 & 0.6 & $* * *$ & 0.6 & 70 & 21. & 0.4 & 225 & 121 & 59.5 & 3 & MSW (Across \\
\hline & & & & & & & & & 5 & & & & & & Europe) \\
\hline & 11.5 & 9.6 & 22.9 & 0.1 & 0.7 & $* \star *$ & 0.8 & 20 & 6.2 & 0.2 & $* * *$ & 25 & 48 & 1.5 & Industrial \& \\
\hline & & & & & & & & & & & & & & & Commercial \\
\hline & & & & & & & & & & & & & & & Waste \\
\hline \multirow{2}{*}{$\begin{array}{l}\text { Gendebien et al, } \\
2003\end{array}$} & 25 & 20 & 15 & 0.6 & 0.9 & $* * *$ & 7 & 100 & 40 & 7 & 500 & 200 & 300 & 9 & MSW (Italy) \\
\hline & & & & & & & & & & & & & & & \\
\hline \multirow[t]{2}{*}{ Kara, 2012} & $* * *$ & 7.7 & 14.644 & 0.4 & 0.9 & 58 & 1.6 & $\star \star * *$ & $\star \star \star *$ & 0.3 & $* \star *$ & 26.5 & 18.4 & 0.9 & MSW (Turkey) \\
\hline & & & & 6 & 5 & & & & & & & & & & \\
\hline \multirow{6}{*}{$\begin{array}{l}\text { Hernandez-Aton } \\
\text { al et al., } 2006\end{array}$} & 3.7 & 18.9 & $* * *$ & 0.2 & 2.5 & 61. & 2 & 150 & $* * *$ & $* * *$ & 548 & 250 & 805 & 4 & MSW (UK) \\
\hline & & & & & & 2 & & & & & & & & & \\
\hline & 1.7 & 17.7 & $* * \star$ & 0.3 & 1.7 & 69. & 1 & 55 & $* * *$ & $* * *$ & 326 & 343 & 992 & 2 & \\
\hline & & & & & & 1 & & & & & & & & & \\
\hline & 19.7 & 20.4 & 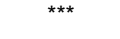 & 0.2 & 1.8 & 57. & 29 & 71 & $* \star *$ & $* \star *$ & 1135 & 245 & 2320 & 4 & \\
\hline & & & & & & 4 & & & & & & & & & \\
\hline
\end{tabular}




\begin{tabular}{|c|c|c|c|c|c|c|c|c|c|c|c|c|c|c|c|}
\hline Compagnone et & $7.8-8.4$ & $15.8-16$ & $\star \star \star *$ & 0.0 & $* * *$ & 55. & 0.8 & 76 & 166 & 0.5 & 445 & 880 & 320 & 0.7 & MSW (Italy) \\
\hline \multirow[t]{3}{*}{ al., 2006} & & .8 & & $3 \pm$ & & $1 \pm$ & & & & & & & & & \\
\hline & & & & 0.0 & & 0.3 & & & & & & & & & \\
\hline & & & & 5 & & & & & & & & & & & \\
\hline \multirow{4}{*}{$\begin{array}{l}\text { Hemidat et al., } \\
2019\end{array}$} & 25 & 16 & 12.84 & *** & 0.5 & $* * *$ & 2.9 & 62 & 53 & $<0.0$ & 280 & *** & $* * *$ & 0.89 & MSW (Jorden) \\
\hline & & & & & 6 & & & & & 3 & & & & & \\
\hline & 34 & 19 & 15.82 & $\star \star \star *$ & 1.2 & $* \star *$ & 3 & 70 & 64 & $<0.0$ & 260 & *** & $* \star *$ & 1.1 & \\
\hline & & & & & & & & & & 3 & & & & & \\
\hline Collected Data & $1.7-34$ & 7.7-20. & 12.84- & 0.0 & 0.5 & 54. & 0.6 & $20-$ & 6.2 & $0.03-$ & $225-$ & $25-8$ & $18.4-$ & $0.89-9$ & \\
\hline \multirow[t]{2}{*}{ Range Values } & & 4 & 22.9 & $3-0$ & $6-2$ & $8-6$ & -29 & 150 & -16 & 7 & 1135 & 80 & 2320 & & \\
\hline & & & & .6 & .5 & 9.1 & & & 6 & & & & & & \\
\hline
\end{tabular}

*Note: Some studies did not record some properties; therefore, the non-recorded properties are not considered as zero in this paper. Also, the presented charts in this paper are based on this table.

\section{RESULTS AND DISCUSSION}

The positive impact of the RDF pellets has been seen in different cities around the world, including Sulaimani city. Sulaimnai city produces about 1,200,000 tons of MSW on daily bases; the MSW is dumped in landfills producing methane gas that is harmful to the environment. The introduced RDF heals about $85 \%$ of this MSW as it converts it into RDF pellets. The energy produced from these RDF pellets currently replaces about $20 \%$ to $30 \%$ of the typical energy used in the factories; and by that this method reduces the harm caused by the
MSW to the environment (Sarwar, 2020).

\subsection{Immediate Analysis}

The RDF pellets go under various analyses that determine its properties. These analyses are applied after the recovery processes of the municipal solid waste. The immediate analysis includes measuring the content value of moisture and ash in the RDF pellets. These two content properties are important to be measured as any excess or surplus amount of them will damage the product's quality, RDF pellets. Therefore, they should exist in the product but within a specific range. 


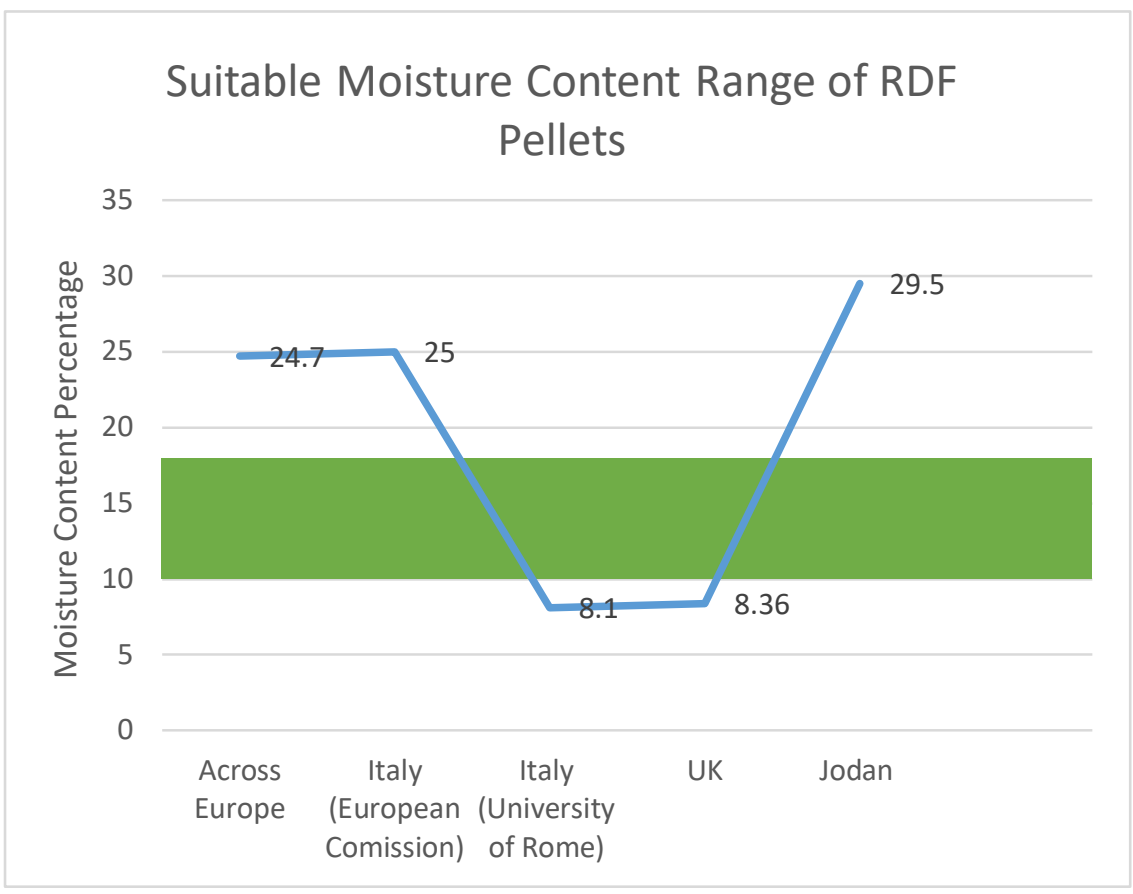

Fig. (4): Suitable Moisture Content-Range of RDF Pellets of MSW

The moisture content should be within the range of $10 \%$ to $18 \%$ as this percentage range is the suitable interval for the process of briquette to produce RDF pellets (Kers et al., 2010; Matuš et al., 2010). If the content value is more than $18 \%$, then the product should undergo a drying process where it loses its excessive amount of moisture. Similarly, if the moisture content is lower than $10 \%$, then "Lover moisture" products should be added to the RDF pellets. In this study, and from the collected data, the range of the moisture content ranged from $1.7 \%$ to $34 \%$. Figure 4 shows the suitability of RDF pellets in the process of briquetting from the collected data.

\subsection{Elementary Analysis}

Sulfur is another factor to be measured in RDF pellets as it reacts with oxygen; producing Sulfur Dioxide during the combustion process. The typical Sulfur content found in crude oil, which is an important factor for producing energy, ranges from $0.05 \%$ to $14 \%$ (Fahim et al., 2010; Yari, 2017). Sulfur in this study ranged from $0.03 \%$ to $0.6 \%$; the majority of the data collected fell within the range that satisfies the production of energy if compared to the Sulfur content found in crude oil as is illustrated in Figure 5.

The Chlorine content in RDF pellets is another important property that should be measured as Chlorine plays a role in the combustion process to produce energy. The typical Chlorine content found in combustors ranged from $0.5 \%$ to $2.5 \%$ "at temperatures as low as 400-500 C" (Procaccini, 1999; Ma et al., 2020). The Chlorine content values of this study ranged from $0.56 \%$ to $2.5 \%$; the collected data fell in the typical range of Chlorine content as it is illustrated in Figure 6. 


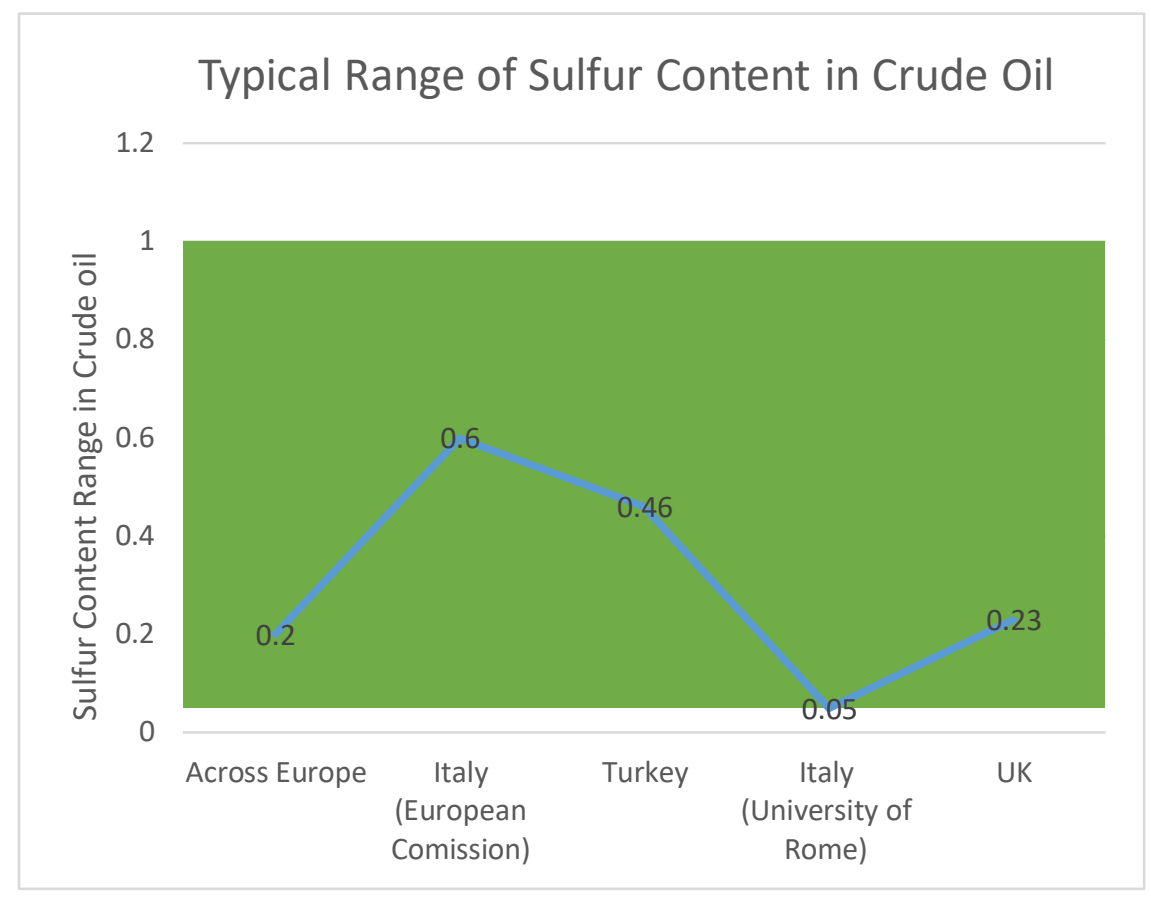

Fig. (5): Typical Range of Sulfur Content in Crude Oil

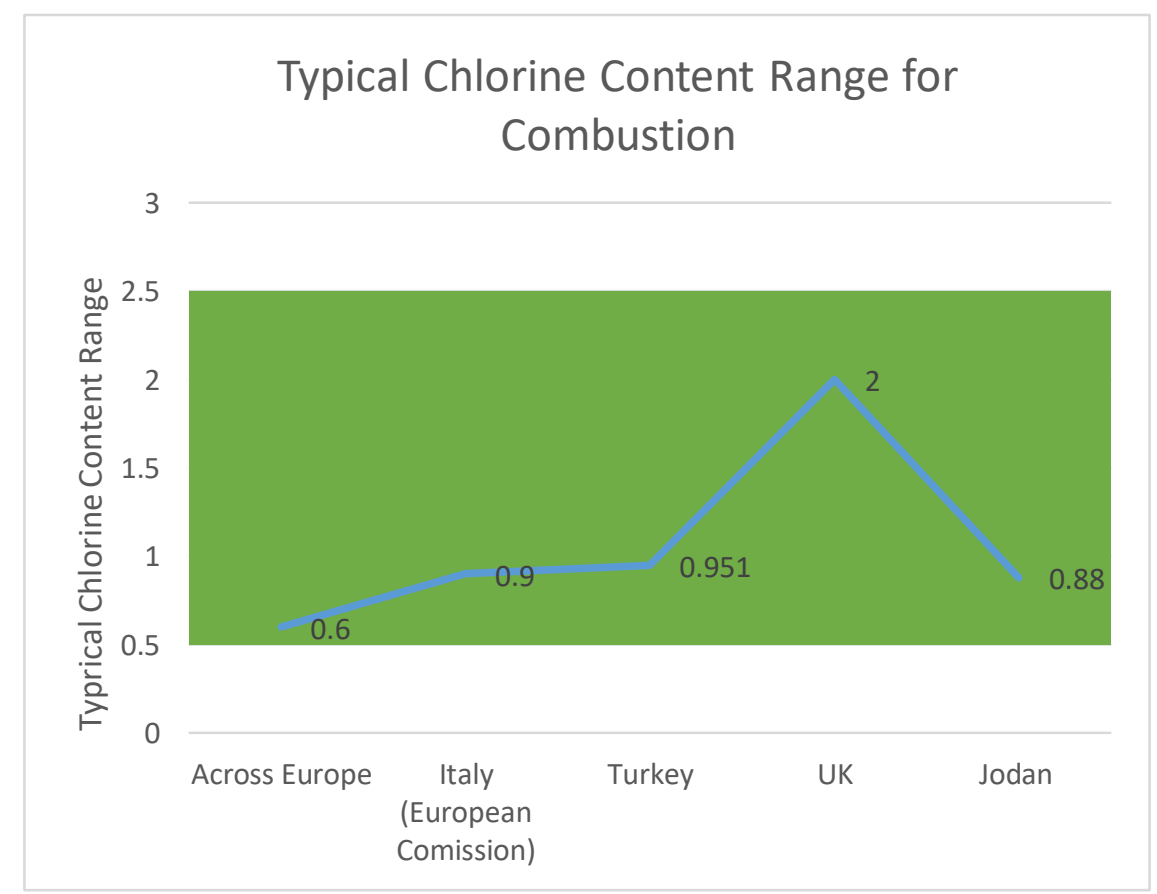

Fig. (6): Typical Chlorine Content-Range in Combustion

Carbon is an important element in fossil fuel for producing energy as the process of producing energy is dependent on the heat produced when Carbon is burnt (Radford, 2013). Therefore, it is an important factor to be measured in the produced RDF pellets from the MSW as it plays a role in the interest of producing energy. The Carbon content in this study ranged from $54.8 \%$ to $69.1 \%$. The Carbon content was significantly higher than the other property content values as it is illustrated below. 


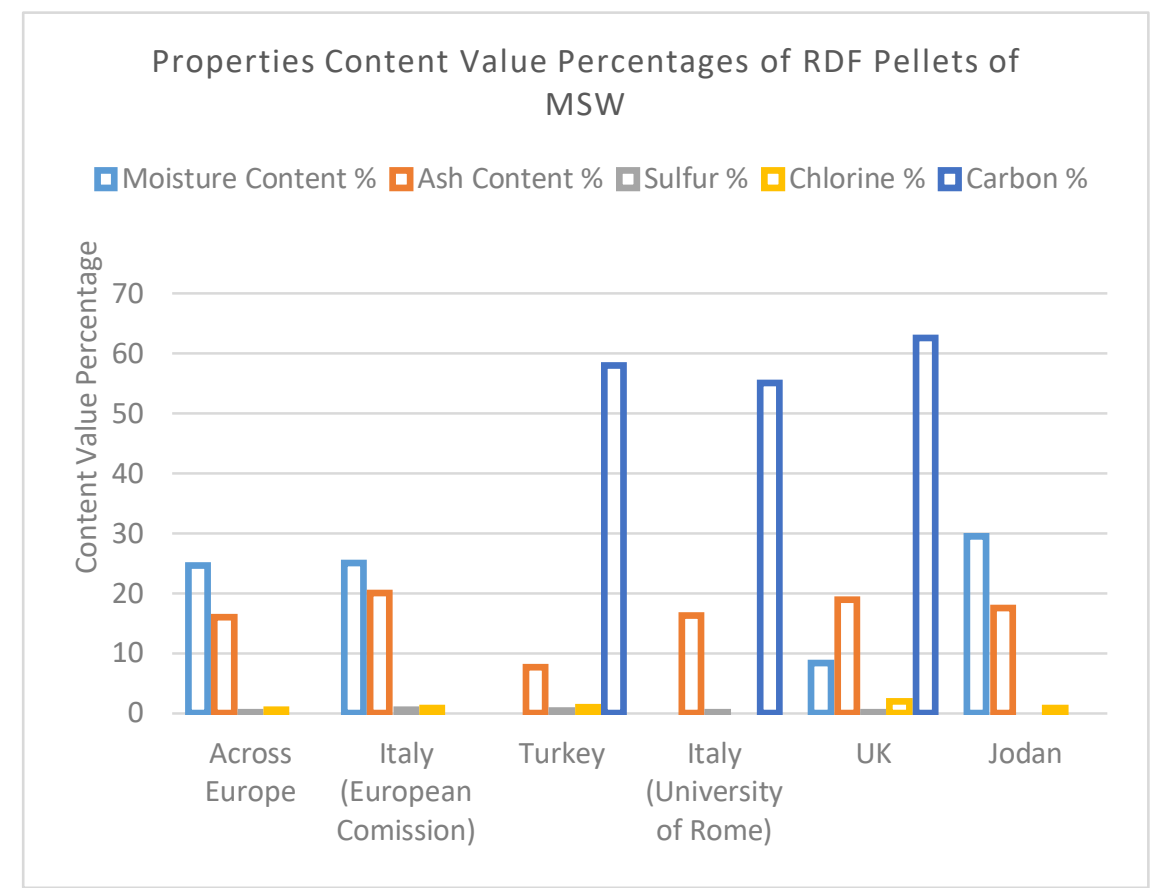

Fig. (7): Content Value Percentages of RDF Pellets of MSW in Different Countries

\subsection{Trace Element Analysis}

Since MSW is taking too many lands and the treatments of MSW (incineration and biological) are found to harm the environment, RDF is the best alternative to make the MSW a less environmentally harmful source of energy.

During the gasification method of RDF, unwanted "organic pollutants" by-products might be formed when reacting with the heavy metals such as $\mathrm{Pb}, \mathrm{Cd}, \mathrm{Zn}, \mathrm{Cr}, \mathrm{Ni}, \mathrm{As}$, and $\mathrm{Hg}$ that are represented in the ash content of the
RDF pellets. It was found that during the gasification method; of an average length RDF pellet, $15 \mathrm{~mm}$ to $20 \mathrm{~mm}$ and a diameter of $7 \mathrm{~mm}$, that the heavy metals; in the high-temperature range of $600 \mathrm{C}^{\circ}$ to $750 \mathrm{C}^{\mathrm{o}}$, will move to the air or accumulate in the soil and harm the environment, except for $\mathrm{Cd}$ as it needs higher temperatures (Zhou, et. al, 2016). Therefore, it is important to indicate the content value of each heavy metal found in the RDF pellets. The range of the collected data is set to be as in Table 2 .

Table (2): The ranges of Heavy Metals in RDF Pellets from MSW

\begin{tabular}{cccccccc}
\hline Cd mg/kg & Cr mg/kg & Ni mg/kg & Hg mg/kg & Zn mg/kg & Pb mg/kg & Cu mg/kg & As mg/kg \\
\hline $0.6-29$ & $20-150$ & $6.2-166$ & $0.03-7$ & $225-1135$ & $25-880$ & $18.4-2320$ & $0.89-9$ \\
\hline
\end{tabular}


It can be noticed that unlike the other metals, the amount of $\mathrm{Zn}$ and $\mathrm{Pb}$ are very high while the amounts of $\mathrm{Cd}$ and $\mathrm{Hg}$ rank the least as these heavy metals, generally, are extracted from "goods such as cans, cables, zippers, or batteries which are highly concentrated in metals" like $\mathrm{Pb}$ and $\mathrm{Zn}$ (Skutan and Brunner, 2012). Figure 8 represents the numerical amount of heavy metals in RDF pellets derived from MSW from different countries.

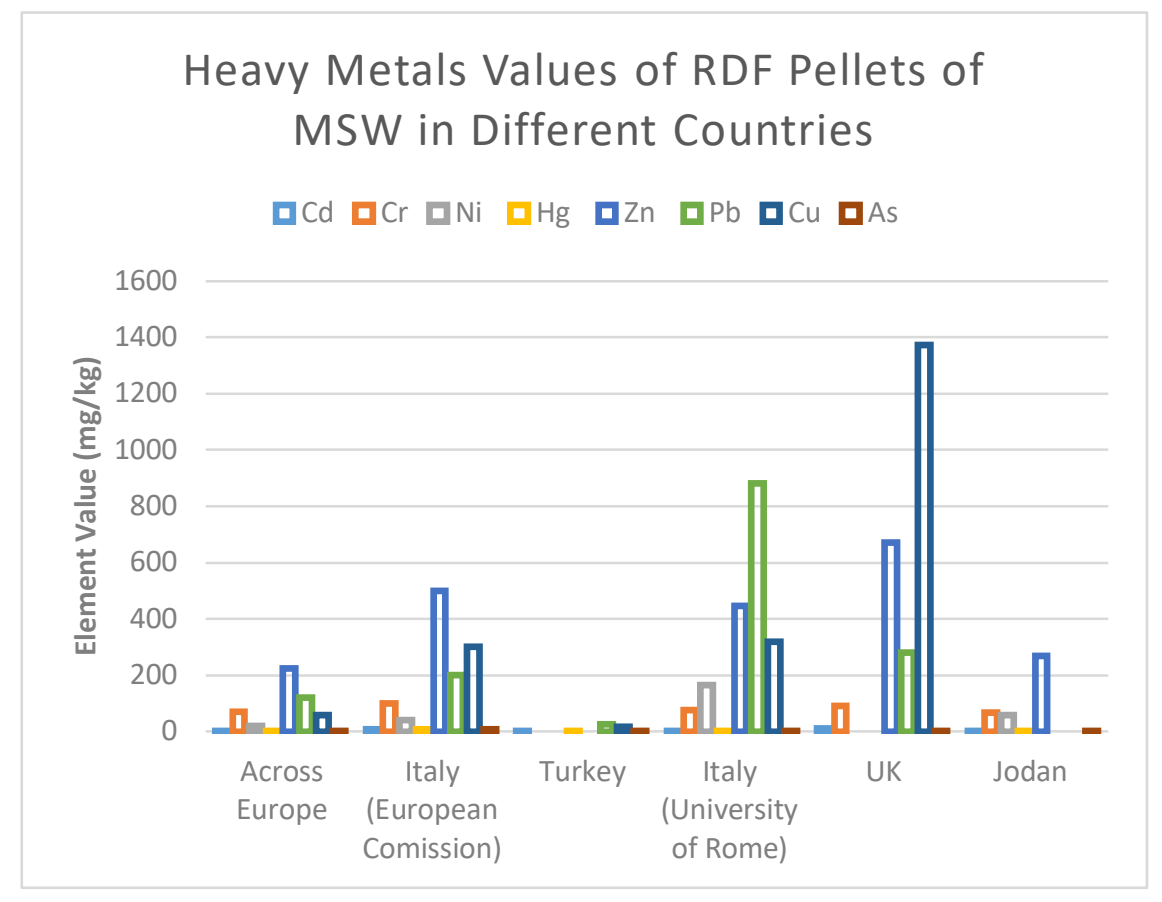

Fig. (8): Heavy Metals Values of RDF Pellets of MSW in Different Countries

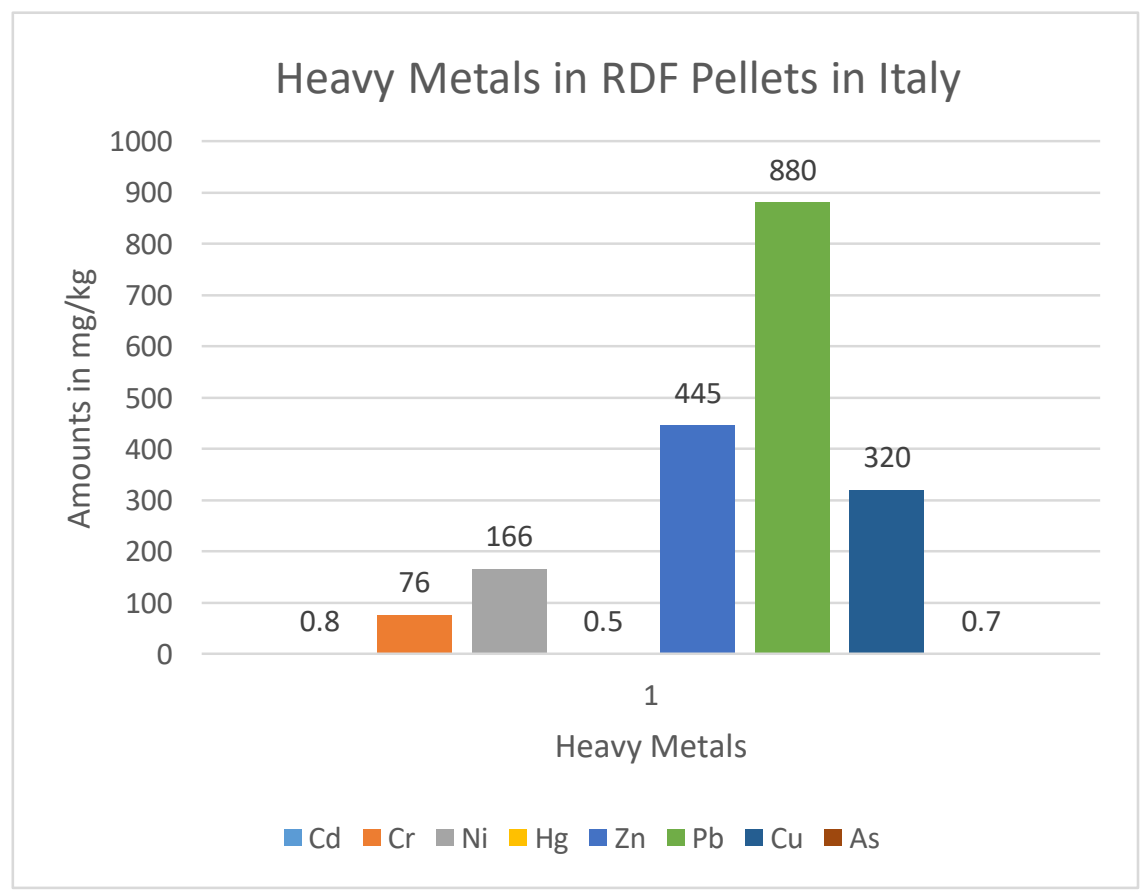

Fig. (9): Heavy Metals in RDF Pellets across Europe 
As represented in Figure 9, for the RDF pellets from the data collected from across Europe, the amount of $\mathrm{Zn}$ is the highest with a value of $225 \mathrm{mg} / \mathrm{kg}, \mathrm{Pb}$ is ranked in second place with a value of $121 \mathrm{mg} / \mathrm{kg}$. The least amount is
$\mathrm{Hg}$ with a value of $0.4 \mathrm{mg} / \mathrm{kg}$; these amounts are from wastes collected from apartments and offices from 752 samples (Gendebien et al, 2003).

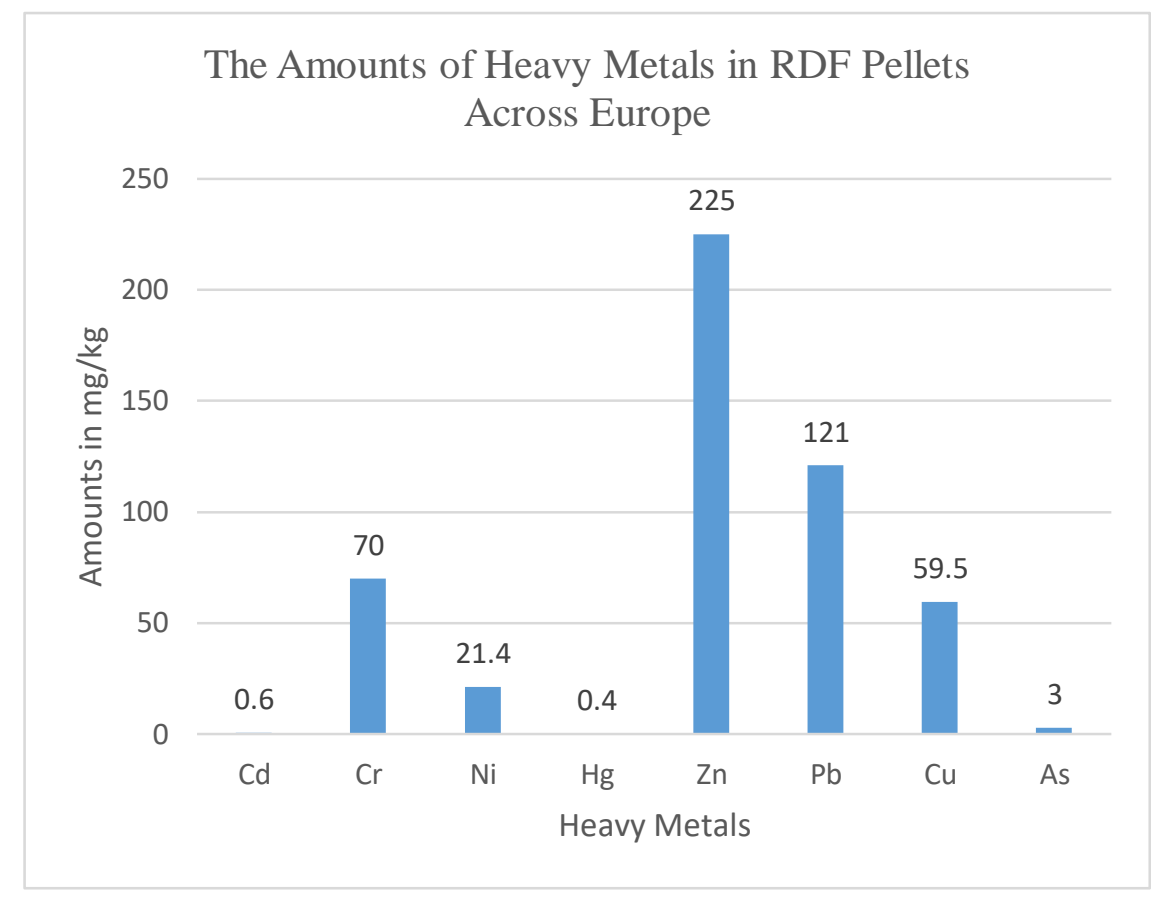

Fig. (10): Heavy Metals in RDF Pellets in Italy

Figure 10 shows the amount of heavy metal from MSW in Italy. The highest amount is for $\mathrm{Pb}$ with a value of $880 \mathrm{mg} / \mathrm{kg}$. $\mathrm{Zn}$ is ranked in second place with a value of $445 \mathrm{mg} / \mathrm{kg}$ and $\mathrm{Hg}$ ranks the least with a value of $0.5 \mathrm{mg} / \mathrm{kg}$. These values are expected to be ranked like this; usually $\mathrm{Hg}$ ranks the least while $\mathrm{Pb}$ and $\mathrm{Zn}$ ranks the highest.

\subsection{Calorific Value}

To determine how much energy, the material can produce, the calorific value is to be considered after the end of the combustion. Many factors can affect the amount of the calorific value, for example, the calorific value changes with the change of the moisture and ash content, an increase in the moisture and ash content presented in the fuel leads to a decrease in the calorific value of that fuel. The reason lies behind that the high moisture value in the fuel means higher water amount; hence it needs more energy to be burnt. The ash content on itself is a result of incombustible materials that result after the end of the combustion.

The standard amount of calorific value (HHV) produced by the RDF is $18 \mathrm{MJ} \mathrm{kg}-1$ and it is sufficient compared to the standard amount of calorific value in raw MSW fuel which is 9.1 MJ kg-1 (Zhao et al, 2016). In other words, the calorific value represents the amount of energy released as heat after the complete combustion with the presence of oxygen. In this study, the data were collected from Turkey, Jordan, Italy, and across Europe ranging between $13.3 \mathrm{MJ} \mathrm{kg}-1$ to $15 \mathrm{MJ} \mathrm{kg}-1$ as represented in Figure 11. 


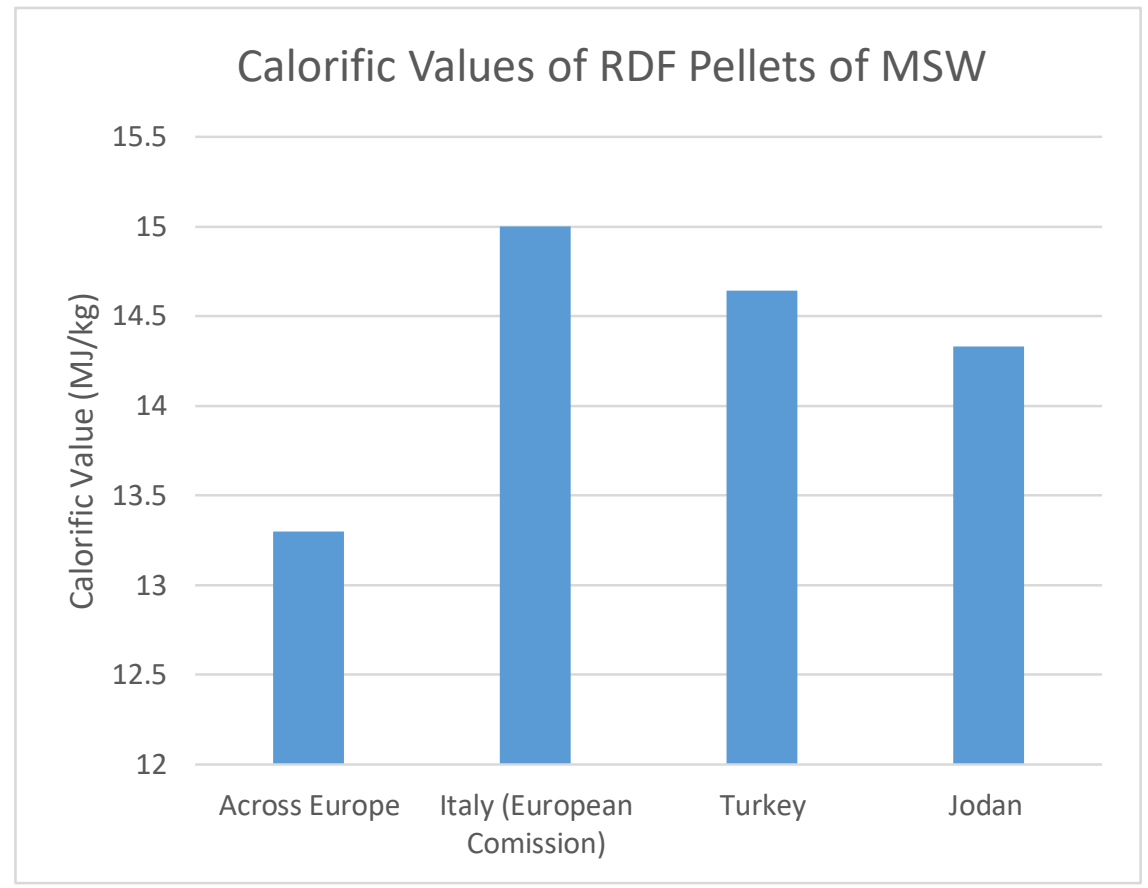

Fig. (11): Calorific Values of RDF Pellets of MSW in Different Countries

\section{CONCLUSION}

-In conclusion, the positive environmental impact of RDF pellets was conveyed in this paper as these RDF pellets reduces the harm that is caused by landfilling through which it eliminates the landfills by deriving different forms of energy from municipal solid waste (MSW).

-The analyzed parameters presented in this paper determined the typical quality of RDF pellets when derived from municipal solid waste (MSW) from different countries.

-Each parameter, including moisture content, ash content, Sulfur content, Chlorine content, Carbon content, heavy metals content $(\mathrm{Cd}, \mathrm{Cr}$, $\mathrm{Ni}, \mathrm{Ag}, \mathrm{Zn}, \mathrm{Pb}, \mathrm{Cu}, \mathrm{As}$ ), and Calorific values had its typical range and numerical amount presented in these RDF pellets.

-None of the moisture content values from the collected data fell within the typical range of moisture content found in RDF pellets. In contrast to the moisture content, the Sulfur content and the Chlorine content from the collected data fell within their typical ranges while the Carbon content ranked the highest.

-Regarding the heavy metals, the two heavy metals, $\mathrm{Pb}$ and $\mathrm{Zn}$, were found to be ranked the highest from almost all the selected data while $\mathrm{Hg}$ ranked the least.

-The Calorific value from the collected data ranged from $13.3 \mathrm{MJ} \mathrm{kg-1}$ to $15 \mathrm{MJ} \mathrm{kg}-1$. This value represents the amount of energy produced from the RDF pellets; hence, the amount of energy produced as heat.

\section{ACKNOWLEDGMENTS}

Special thanks to Dr. Ahmed Salih, a professor at the American University of Iraq-Sulaimani, who supervised our work in writing this paper. 


\section{REFERENCES}

Abraham, B., Araya, H., Berhe, T. (2014). The system of crop intensification: reports from the field on improving agricultural production, food security, and resilience to climate change for multiple crops. Agric \& Food Secur.

Adedeji et al. (2014). Global Climate Change. Journal of Geoscience and Environment Protection.

Compagnone, G., De Filippis, P., Scarsella, M., Verdone, N. \& Zeppieri, M. (2006). Heavy metal behavior during RDF gasification. Researchgate. Rome, Italy.

Asati, Ambika., Pichhode, Mohnish. \& Nikhi, Kumar. (2016). Effect of Heavy Metals on Plants: An Overview. International Journal of Application or Innovation in Engineering \& Management. India.

Fahim, Mohamed., Alsahhaf, Taher. \& Elkilani, Amal. (2010). Fundamentals of Petroleum Refining. Kuwait University. Khaldeya, Kuwait.

Fitzgerald, Garrett. \& Themelis, Nickolas J. (2009). Technical and economic analysis of pre-shredding municipal solid wastes prior to disposal.

Gendebien, A., Leavens, A., Blackmore, K., Godley, A., Lewin, K., Whiting, K.J., \& Davis, R.

(2003). Refuse Derived Fuel, Current Practice and Perspective. European Emissions-

Directorate General Environment.

Hemidat, S., Saidan, M., Al-Zu'bi, S., Irshidat, M., Nassour, A., \& Nelles, M. (2019). Potential Utilization of RDF as an Alternative Fuel for the Cement Industry in Jordan. Sustainability. Amman, Jordan.

Hernandez-Atonal F. D., Ryu, C, Sharifi, V \& Swithenbank, J. (2006). Combustion of refuse-derived fuel in a fluidised bed. Sheffield University. Sheffield, UK.
Kara, M. (2012). Environmental and economic advantages associated with the use of RDF in cement kilns. Marmara Research Center. Gebze, Turkey.

Kers, Jaan., Kulu, Priit., Aruniit, Aare., Laurmaa, Viktor., Križan, Peter., Šooš, Lubomir. \& Ülo, Kask. (2010). Determination of physical, mechanical and burning Characteristics of polymeric waste material briquettes. Estonian Journal of Engineering. Estonia.

Ma, Wenchao., Terrence, Wenga,., Frandsen, Flemming J., Beibei, Yan. \& Guanyi, Chen. (2020). The fate of chlorine during MSW incineration: Vaporization, transformation, deposition, corrosion and remedies. China

Malinauskaite J., Jouhara H., Czajczynska D., Stanchev P., Katsou E., Rostkowski P., Thorne R.J., Colon J., Ponsa

Matúš, M., Križan, P., Šooš, L., Kers, J., Peetsalu, P., Kask, Ü., \& Menind, A. (2011). Briquetting of municipal solid waste by different technologies in order to evaluate its quality and properties. Agronomy Research Biosystem Engineering Special Issue. Slovakia.

Procaccini, Carol (1999). The Chemistry of Chlorine in Combustion Systems and the Gas Phase of Chlorinated and Oxygenated Pollutants. Massachusetts Institute of Technology. USA.

Radford, Tim (2013). Waste Carbon Dioxide Could Be Used as Energy. Climate Home News. The Netherlands.

Riedy, Chris. (2016). Climate Change. University of Technology Sydney. Australia.

S., Al-Mansour F., Anguilano L., Krzyzynska R., Lopez I.C., Vlasopoulos A. \& Spencer N. (2017). Municipal solid waste management and waste-to-energy in the context of a circular economy and energy recycling in Europe. Manik Ventures Limited. UK. 
Sapuay, Grace P. (2015). Resource Recovery through RDF: Current Trends in Solid Waste Management in the Philippines. International Conference on Solid Waste Management. Philippines.

Sarwar, Warzer. (2020). Producing Energy from Dirt, Trash, and House Waste of the City of Sulaimani. Rudaw Sulaimani, Iraq.

Seltenrich, Nate (2016). Emerging Waste-to-Energy Technologies Solid Waste Solution or Dead End? Environmental Health Perspectives. USA.

Singh, Jiwan. \& Kalamdhad, AjayS. (2011). Effects of Heavy Metals on Soil, Plants, Human Health and Aquatic Life. Indian Institute of Technology Guwahati. Guwahati, India.

Skutan, Stefan, Brunner, Pual H. (2012). Metals in $\mathrm{RDF}$ and other high calorific value fractions from mechanical treatment of MSW: Analysis and sampling errors. Waste Management \& Research.
Tchounwou, P. B., Yedjou, C. G., Patlolla, A. K., \& Sutton, D. J. (2012). Heavy metal toxicity and the environment. Experientia Supplementum.

Yari, Mehdi (2017). The 6 Corrosive Components That Can be found in Crude Oil. University of Western Ontario. Canada.

Zhao et al. (2016). Characterization of Singapore RDF resources and analysis of their heating value. Residues and Resource Reclamation Centre, Nanyang Environment and Water Research Institute, Nanyang Technological University, Singapore, 637141, Singapore, School of Civil and Environmental Engineering, Nanyang Technological University, Singapore, 639798. Singapore.

Zhou et al. (2016). Study on heavy metals conversion characteristics during refused derived fuel gasification process. School of Materials and Metallurgy, Northeastern University. 